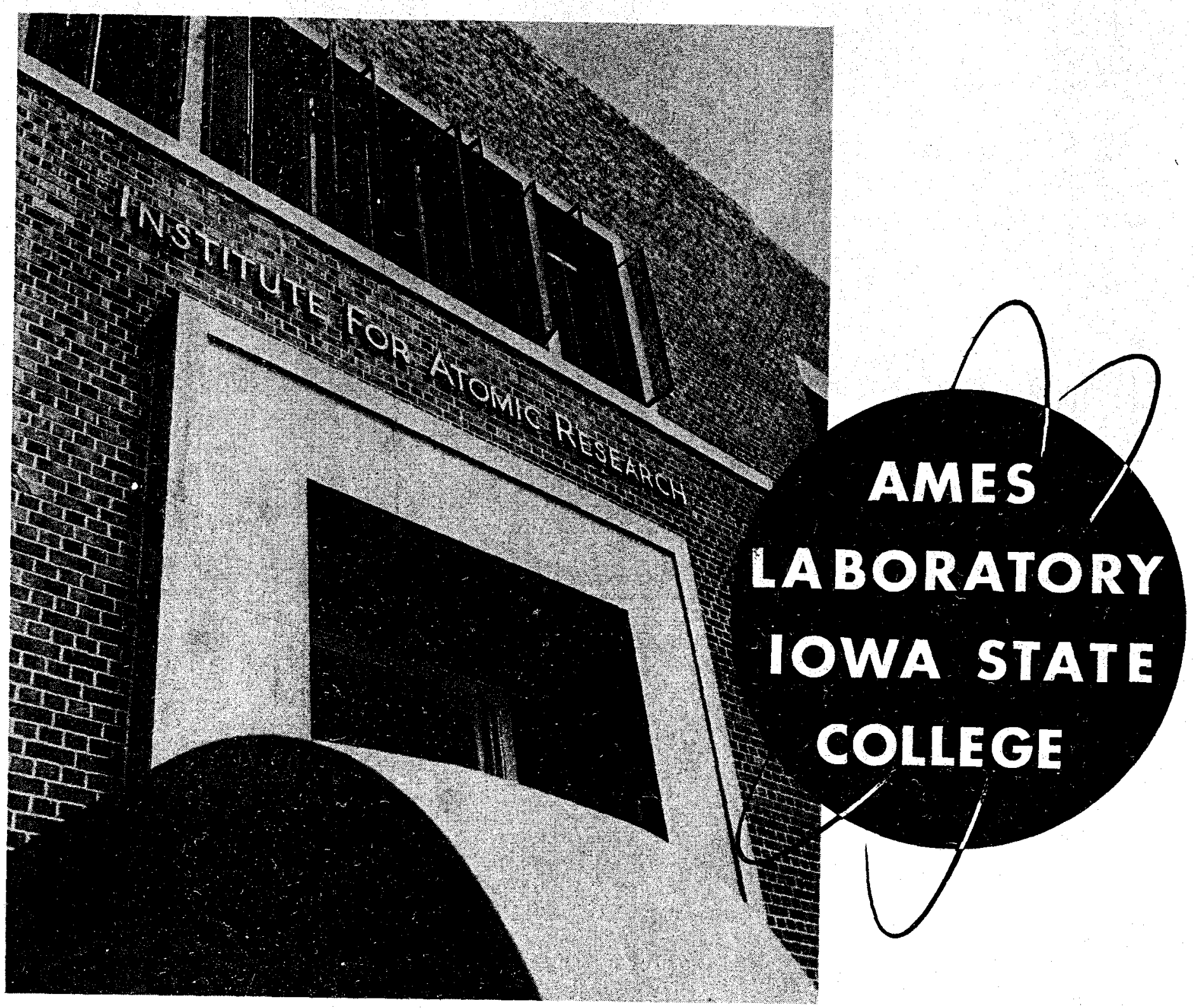

PHYSICS. QUARTERLY SUMMARY RESEARCH REPORT JULY, AUGUST, AND SEPTEMBER, 1954 


\section{DISCLAIMER}

This report was prepared as an account of work sponsored by an agency of the United States Government. Neither the United States Government nor any agency Thereof, nor any of their employees, makes any warranty, express or implied, or assumes any legal liability or responsibility for the accuracy, completeness, or usefulness of any information, apparatus, product, or process disclosed, or represents that its use would not infringe privately owned rights. Reference herein to any specific commercial product, process, or service by trade name, trademark, manufacturer, or otherwise does not necessarily constitute or imply its endorsement, recommendation, or favoring by the United States Government or any agency thereof. The views and opinions of authors expressed herein do not necessarily state or reflect those of the United States Government or any agency thereof. 


\section{DISCLAIMER}

Portions of this document may be illegible in electronic image products. Images are produced from the best available original document. 


$$
\underline{U} \underline{N} \underline{C} \underset{(I S C-533)}{I} \underline{\mathrm{S}} \underline{\mathrm{I}} \underline{\mathrm{F}} \underline{\mathrm{I}} \underline{\mathrm{E}} \underline{\mathrm{D}}
$$

\title{
QUARTERLY SUMMARY RESEARCH REPORT IN PHYSICS \\ For July, August, and September, 1954
}

\author{
by
}

Ames Laboratory Staff

December 21, 1954

\begin{abstract}
Ames Laboratory
at

Iowa State College

F. H. Spedding, Director

Contract $\mathrm{W}-7405$ eng-82
\end{abstract}

$\underline{U} \underline{N} \underline{C} \underline{I} \underline{A} \underline{S} \underline{S} I \underline{F} \underline{I} \underline{E} \underline{D}$

$\because 0+01$ 
This report is distributed according to the category Physics and Mathematics as listed in M-3679, October 15, 1954. 
TABLE OF CONTENTS

PHYSICS

Theoretical Physics

1. Magnetic Studies. . . . . . . . . . 5

\section{Experimental Physics}

1. Nuclear Studies ............. . 5

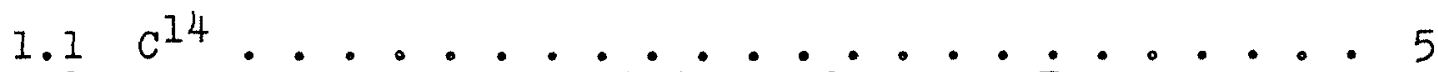

1.2 A Search for Smail Order Effects in Beta

Spectrum. . . . . . . ...... 6

1.3 Assignment of Transition Multipole Orders from

L Subshell Internal Conversion Coefficient Ratios 7

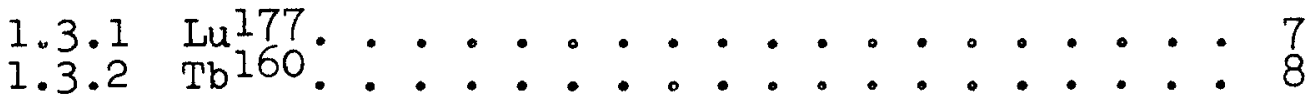

1.4 Ionization Experiments. . . . . . . . 8

1.4.1 Fission Fragment Ionization Yield. $\cdot \dot{1} \cdot 8$

1.4 .2 Ionization Yield from the $\mathrm{B}^{10}(n, \dot{\alpha}) \dot{\mathrm{L} i} \dot{7}$

Reaction..............9

1.5 Cloud-Chamber Identification of Photodeuterons

from Sulfur . . . . . . 10

$1.6 \mathrm{X}$-Ray Induced Radioactivities ........ 10

2. Solid State studies............. . 11

2.1 Thermal Conductivity $(K)$ of Uranium ...... 11

2.2 Semiconducting Metallic Compounds...... 11

2.3 Measurement of Magnetic Fleld Gradients by

the Hall Effect ................ Il

2.4 Electrical Properties of Thin Metalic Films. . II

2.5 Heat of Sublimation of Dysprosium ....... 12

APPENDIX: LIST OF REPORTS FROM THE AMES LABORATORY . • . 13

1. Reports for Cooperating Laboratories ......13

2. Papers Published in Scientific Journals.: : 14 


\title{
QUARTERLY SUMMARY RESEARCH REPORT IN PHYSICS
}

For the Period July, August, and September, 1954

\author{
This report is prepared from material \\ submitted by the group leaders of \\ the Laboratory
}

Previous quarterly research reports in this series are:

$$
\begin{aligned}
& \text { ISC }-35 \\
& \text { ISC-4 } 4 \\
& \text { ISC-56 } \\
& \text { ISC-69 } \\
& \text { ISC-74 } \\
& \text { ISC-76 } \\
& \text { ISC-79 } \\
& \text { ISC-113 } \\
& \text { ISC-130 } \\
& \text { ISC-133 } \\
& \text { ISC-137 } \\
& \text { ISC-171 } \\
& \text { ISC-193 } \\
& \text { ISC-220 } \\
& \text { ISC-246 } \\
& \text { ISC-283 } \\
& \text { ISC- } 301 \\
& \text { ISC-338 } \\
& \text { ISC-395 } \\
& \text { ISC-422 } \\
& \text { ISC-45I } \\
& \text { ISC- }-508
\end{aligned}
$$

Goi $00^{4}$ 


\section{PHYSICS}

Under the direction of F.H. Spedding, G. W. Fox, G. C. Danielson, D. E. Hudson, E. N. Jensen, J. M.

Keller, J.K. Knipp, S. Legvold, G。H. Miller and $D$. J. Zaffarano

\section{Theoretical Physics}

1. Magnetic Studies (J.M. Keller)*

A previous calculation on the combined effect of crystal field and exchange energies on specific heat has been improved. The original calculation was the outcome of a suggestion by Dr. F. H. Spedding of a simple approximate way to include exchange effects. The first calculation was based on a "collective electron" approach, and this calculation was repeated on a "nearest neighbor" basis. The resulting equations are rather complicated, but a numerical example has shown that the results are not terribly different from those obtained from the simpler model. Both calculations indicate a sharp discontinuity in specific heat at the curie temperature.

Theoretical studies on the magnetic properties of dysprosium, based on Elliott'sl data, have been continued. Certain aspects of the data suggest an antiferromagnetic region at temperatures between the ferromagnetic region (below $92^{\circ} \mathrm{K}$ ) and the paramagnetic region (above $176^{\circ} \mathrm{K}$ ). The work of smarte on cubic structures, based on the "molecular field approximation," has been extended to hexagonal structures. This type of theory seems too simple to explain the sharp rise in susceptibility as temperature is lowered, approaching the ferromagnetic curie point. This rise is typical of ordinary (transition element) materials above a curie point, but it is not expected in the familiar antiferromagnetic materials.

\section{Experimental Physics}

1. Nuclear Studies

$$
1.1 \quad \mathrm{C}^{14}(\mathrm{E} . \mathrm{N} \text {. Jensen) }
$$

The results of previous investigations on the beta spectrum of $\mathrm{C}^{14}$ have been in general agreement on the maximum beta energy, but there has been some question as to the shape of the spectrum.

The beta spectrum of $\mathrm{C}^{14}$ has been examined with the intermediateimage spectrometer. With a vacuum evaporated source (the source preparation has been described in ISC-508) consisting of $6 \pm 2 \mu \mathrm{g} / \mathrm{cm}^{2} \mathrm{Li}_{2} \mathrm{CO}_{3}$ on a collodion backing of $6 \pm 2 \mu \mathrm{g} / \mathrm{cm}^{2}$

IJ.F.Elliott, S。 Legvold and F.H. Spedding, Phys. Rev. 94, 11431145 (1954).

${ }^{2}$ J. S. Smart, Revs. Modern Phys。25, 327 (1953)。

* Name indicates group leaders in charge of work. 
It was found that the Kurle plot was Iinear above 7 kev after correcting for the efficiency of the scintillation detector. This source was prepared from a sample kindly supplied by Dr. C. S。Wu (Columbia University, New York City, New York) and was enriched to about $40 \%$ in CI4. The maximum energy of the beta spectrum was found to be $158.5 \pm 0.5 \mathrm{Mev}$. These data are consistent with the interpretation of an allowed transition for cl4 according to $G-T$ selection rules with $\Delta I=1$, no.

\section{$1.2 \frac{\text { A Search for Small Order Effects in Beta Snectra }}{(\text { E. N. Jensen })}$}

An intermediate-image spectrometer and a thin-lens spectrometer have been used to carefully examine the beta spectra of $\mathrm{P} 32, \mathrm{~K} 42$, and $A s 76$.

The P32 spectrum was examined for a Flerz-type deviation using a vacuum evaporated source having a surface density of $3 \mu \mathrm{g} / \mathrm{cm}^{2}$ on a $30 \mu \mathrm{g} / \mathrm{cm}^{2}$ film. Within experimental error no deviation was found from a linear Kurle plot. The value of "r" describing the magnitude of the Fierz deviation as defined by Davidson and Peaslee 1 was found to be $0.00 \pm 0.03$. The maximum energy of the beta spectrum was found to be $1.712 \pm 0.005 \mathrm{Mev}$.

The first forbidgen transitions of the lower-energy beta groups of $K^{4} 2$ and $A s 76$ with $\Delta I=0$, yes, were examined for deviation from a linear Kurie plot. "The calculated "shape factors" of Mahmoud and Konopinski2 indicate that the deviations should be largest for high energy transitions of low $Z$ nuglei and that the deviations should be observable for $\mathrm{K}^{42}$ and $\mathrm{As} 76$. Within experimental error no deviations were found. A deviation of the $K^{42}$ Kurie plot below $500 \mathrm{kev}$ was attributed to an additional beta group. The $\mathrm{K}^{42}$ vacuum-evaporated source had a surface density of $20 \mu \mathrm{mg} / \mathrm{cm}^{2}$ on a backing of $30 \mu \mathrm{g} / \mathrm{cm}^{2}$. The As76 source was evaporated from solution and had an average surface density of about $0.5 \mathrm{mg} / \mathrm{cm}^{2}$ on a $30 \mu \mathrm{g} / \mathrm{cm}^{2}$ collodion film.

The maximum energies of the $\mathrm{K}^{42}$ beta groups were found to be $3.545+0.015 \mathrm{Mev}$ and $1.985+0.010 \mathrm{Mev}$. A third weak beta group had a maximum energy of about $0.5 \mathrm{Mev}$. Two gamma rays were found for $\mathrm{K}+2$ with energies of $1.53 \pm 0.01 \mathrm{Mev}$ and $320 \pm 5 \mathrm{kev}$. The $320 \mathrm{kev}$ gamma ray has an intensity of $0.8+0.8 \%$ of that of the 1.53 Mev gamma ray.

The maximum energies of the three higher-energy beta groups of As 76 were found to be $2.97 \pm 0.01 \mathrm{Mev}, 2.42 \pm 0.01 \mathrm{Mev}$, and $1.77 \pm 0.02$ Mev.

IJ. P. Davidson and D. C. Peaslee, Phys. Rev. 91,1232 (1953). 2H. M. Mahmoud and E. J. Konopinski, Phys。Rev. 88, 1266 (1952). 
1.3 Assignment of Transition Multipole Orders from L Subshell Internal Conversion Coefficient Ratios (E.NoJensen)

Using a variable fleld $180^{\circ}$ beta spectrometer and very high specific activities, it was possible to determine I subsheli conversion ratios for both the $112.0 \mathrm{kev}$ transition in Lul77 and the 85. 1 kev transition in $\mathrm{Tb} 160$.

Magnetic field monitoring and measurement were done in a unique manner sultable only for low energy spectrometers. Accelerated electrons from a tungsten fllament were focused by the field into a semi-circle. This beam current was detected by two adjacent carbon plates connected to a balanced electrometer. The field was adjusted so as to keep the current to the two plates equal for a given accelerating voltage. Accelerating voltages of 200 to 5000 volts gave the spectrometer a range of 10 to $200 \mathrm{kev}$.

$$
1.3 .1 \quad \underline{\mathrm{Lu}} 177
$$

For the $112.0 \mathrm{kev}$ transition in $\mathrm{Lu}^{177}$ decay the $\mathrm{L}_{\mathrm{I}} / \mathrm{I}_{\mathrm{II}} / \mathrm{I}_{\mathrm{III}} / \mathrm{M}$ ratio was found to be $<0.05 / 1.14 \pm 0.02 / 1.00 / 0.62 \pm 0.02$. E2 theoretical estimates for these ratios are $0.11 \pm 0.03 / 1.14 \pm 0.03 / 1.00$. The conclusion that this 112.0 kev transition $1 \mathrm{~s}$ E2 agrees with the identical conclusion reached by of hers on the basis of angular correlation and the $K$ shell laternal conversion coefifclent, and the $K / \mathrm{I}$ ratio.

In order to give a check on the E? assignment for the $112 \mathrm{kev}$ transition in Lulf., the beta and internal conversion spectra were determined with the intermediate-image spectrometer with a vacuum evaporated source having of surface density of $3 \mu \mathrm{g} / \mathrm{cm}$ ? on a $25 \mu \mathrm{g} / \mathrm{cm}^{2}$ collodion film. Colncidence beta spectra were also obtained. From tnese data the $K / L / M$ ratio for this transition was $0.64 \pm 0.02 / 1.00 / 0.28+0.01$. Although the $K /$ L tatio is somewhat above the empirical curve of Goldhaber and Sunyar for E? radiation, recent re-evaluation of points on the Goldhaber and Sunyar curve suggest that the curve is posgibiy a bit low for this region of $Z^{2}$ E. The $K$ conversion coefficient was found to be $\alpha K_{K}=0.4 \pm 0.2$. The large error is due to the uncertainty in the branching ratios.

Confirmation of the El assignment to the 208.7 kev transition was obtalned from $K$ conversion coefileient, $\alpha_{K}=0.041 \pm 0.010$.

Coincidence spectra of the two low energy beta and total spectrum on the high energy group gave no indication of departure from a straight line in their kurie plots. Log $20\left(\mathrm{~W}_{0}^{2}-1\right) \mathrm{ft}$ values for the three groups were too low to expect any $S$-shaped Kurie plots. All three beta groups, therefore, appear to be first-forbidden. Based on a $\mathrm{pl} / 2$ ground state for $\mathrm{Hf} 177$ from the shell model, the first-forbiddeness of the two high energy beta transitions, and the EQ character of the 112.0 kev transition, the ground state of Lul77 is assigned to a $\mathrm{d}_{3 / 2}$ level. 
End points of the beta groups, in order of increasing energy as determined from coincidence and total spectra, were found to be $180 \pm 2 \mathrm{kev}, 388 \pm 3 \mathrm{kev}$ and $507 \pm 2 \mathrm{kev}$, and the branching ratios were found to be $9 \%, 17 \%$, and $74 \%$ respectively. From the conversion lines the two lower-energy gamma-rays were found to have energies of $112.0+0.2 \mathrm{kev}$ and $208.7 \pm 1.4 \mathrm{kev}$. The energy of the highest-enexgy gāmma ray was not determined. The decay scheme determined from these data is in agreement with that of D. G. Douglas. 1

$$
1.3 .2 \quad \mathrm{~Tb}^{160}
$$

The $85.1 \mathrm{kev}$ transition conversion ratios in $\mathrm{Tb}^{160}$ decay were found to be $L_{I} / I_{T I} / L_{T I} / M=0.61+0.10 / 0.87 \pm 0.06 / 1.00 / 0.94 \pm 0.07$. $\mathrm{I}_{\mathrm{I}} / \mathrm{L}_{\mathrm{II}} / \mathrm{L}_{\text {II }}$ ratios determined by theory for $\mathrm{E} \overline{2}$ transitions are $0.3 \pm 0.170 .95 \pm 0.02 / 1.00$ and agree best with the experimental ratios. The $L_{I} / I_{I}$ theoretical ratio is a rapidly varying function of $\mathrm{Z}$ in the region of the $\mathrm{Tb} 160$ da ughter product. Forthcoming theoretical results including screening may prove to be in better agreement with experiments. From these data it is concluded that the $85.1 \mathrm{kev}$ gamma ray in the $\mathrm{Tb} 160$ decay is an E2 transition.

\subsection{Ionization Experiments (G. Miller)$$
\text { 1.4.1 Fission Fragment Ionization Yie1d }
$$

An article entitled "Relative Ionization Yields for Fission Fragments in Various Gases", was published in Phys. Rev. 95. 413-417 (1954).

\section{Abstract}

The ionizations resulting from $\mathrm{U}^{238}$ fission have been measured in He, $\mathrm{Ne}, \mathrm{A}, \mathrm{Kr}, \mathrm{N} 2, \mathrm{~A}+3 \% \mathrm{CO}_{2}$, and $\mathrm{A}+5 \% \mathrm{~N} 2$. Comparison of these values with those obtained for alpha particles in the same chamber filings permit the calculation of ionization defect differences. It was found that about hali of the 7 Mev defect previously ascribed to argon- $\mathrm{CO}_{2}$ mixtures was due to $\mathrm{CO}_{2}$. Nitrogen and krypton exhibited relatively large defects. No significant difference was observed between argon and helium. Several possible explanations for this are suggested and discussed.

The collimated 50 microgram $/ \mathrm{cm}^{2}$ source of natural uranium used previously was replaced by an uncollimated source of the same material having a thickness of about $20 \mathrm{microgram} / \mathrm{cm}^{2}$. The results thus obtained are shown in the following table, along with the results obtained with the thicker source.

${ }^{1}$ D. G. Douglas, Phys。Rev。 15,1960 (1949)。 
Table I

\begin{tabular}{|c|c|c|c|c|c|c|}
\hline \multirow[t]{2}{*}{ Gas } & \multicolumn{2}{|c|}{$\begin{array}{ll}\text { New Results } \\
\text { Mev }\end{array}$} & \multicolumn{2}{|c|}{$E_{f}=E_{\alpha} \underset{\substack{\text { Previous value } \\
\text { Mev }}}{I_{f}}{ }^{I_{f}}{ }^{\text {Mev }}$} & \multicolumn{2}{|c|}{$\begin{array}{c}\text { Difference } \\
\text { Mev }\end{array}$} \\
\hline & Light & Heavy & Light & Heavy & Light & Hea vy \\
\hline Helium & 95.8 & 64.1 & 92.9 & 61.8 & 2.9 & $2 \cdot 3$ \\
\hline Argon & 93.7 & 63.4 & 92.5 & 60.9 & 1.2 & 2.5 \\
\hline Nitrogen & 90.5 & 60.9 & 88.9 & 58.0 & 1.6 & 2.9 \\
\hline $\mathrm{A}+3 \% \mathrm{CO}_{2}$ & ---- & ---- & 89.5 & 56.4 & --- & $-\cdots$ \\
\hline $\mathrm{A}+5 \% \mathrm{CO}_{2}$ & 91.8 & 61.0 & --- & --- & --- & --- \\
\hline $\mathrm{He}+3 \% \mathrm{CO}_{2}$ & 93.1 & 61.9 & --- & ---- & ---- & --- \\
\hline $\begin{aligned}{ }^{I_{E}} & =\text { Energy } \\
I_{f} & =\text { Ioniza } \\
I_{\alpha} & =\text { Ioniza } \\
E_{f} & =\text { Energy }\end{aligned}$ & $\begin{array}{l}\text { of alph } \\
\text { tion by } \\
\text { tion by } \\
\text { of fiss }\end{array}$ & $\begin{array}{l}\text { a partic } \\
\text { fission } \\
\text { alpha pa } \\
\text { ion deri }\end{array}$ & $\begin{array}{l}\text { cle } \\
\text { fragment } \\
\text { article } \\
\text { ived from }\end{array}$ & ionization & & \\
\hline
\end{tabular}

It may be seen that the loss of energy within the source has been reduced by about 2 and $2.5 \mathrm{Mev}$ for the average light and average heavy fragment respectively. This would indicate that perhaps another Mev should be added to each in order to correct for the remaining source thickness.

$$
1.4 .2 \text { Ionization Yield from the } \mathrm{B}^{10}(\mathrm{n}, \alpha) \mathrm{Li}^{7} \text { Reaction }
$$

Using a cylindrical ionization chamber, data were taken in several gas mixtures. The source used was of natural boron and was sprayed on from a boric acid-alcohol solution. The results were not very satisfactory. A very high background appeared in the pulse height distribution, particularly in the region of the Li7 recoil peak. It was possible to get the following results, however. The ratio of ionizations of the alpha particle from the $\mathrm{B} 10$ reaction and the $\mathrm{U} 234$ alpha particles was compared to the known energy ratio of the same particles. For pure argon, the ionization ratio was about $2 \%$ less than the energy ratio, indicating a deficiency of ionization for the low energy alpha. For argon plus $2 \% \mathrm{CO}_{2}$, the difference was even greater, about $2.5 \%$. In argon plus I\% nitrogen the difference was only about $0.5 \%$. 
A gridatype shamber with a smallei effective volume was constructed and is now in ise. A souree of enriched $B 10$ has been prepared by racuum evapuracion of boron metal. The background is now quite low.

\section{5 cloud-Chamber Identideation of photodeuterons from Sulpur (Do to Zarfarano)}

A continuation of the work in this Leboratory on the ratio of photodeuterons to photoprotong jected from various nucle 1 by high energy $x$ mays has led to additlonal resulta with sulfur. A total of 6600 stereoscople photographs were taken of a sulfur plate of thickness equivalent to the range of a 15 Mev proton in a twelve-inch magnetic oloud-chamber. The range of each $x$-rayinduced track was measured and cormected to its air equivalent range by means of the stopping power of the cloud chamber atmosphere measured with 5.303 Mev al pha particles. The curvature and azimuth of each track, ir. a pussed magnetic field of 4000 gauss, were measured and the curvatire was conrected to that of a track

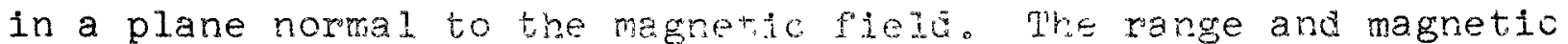
curvature of each track were used to delermine its mass. A mass histogram was plotted which exhibits two well defined peaks at the mass values of a protor and a deiteror. The experimental ratio of

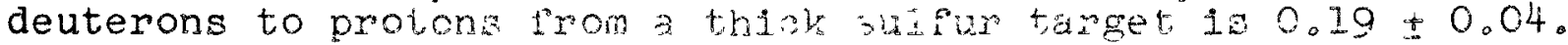

To correct this ratio tor tropt thicknass it was assumed

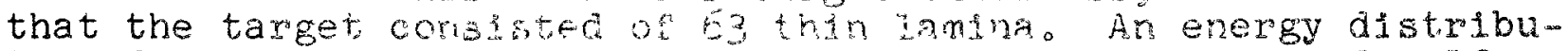
tion for singly charged particer engated from a compound sudfur nucleus was assumed for eact $2 a y e r$. The contributions from all of

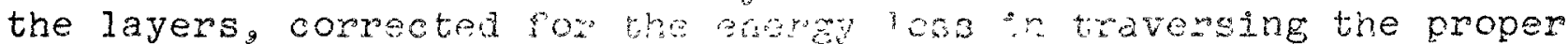
thickness of materiaj, wele then com? :u to five composite energy distributions for the protors and the deuterons that emerged from the thick target. The sangconergy a lations for the cloud-ohamber vapor were different for protons ath for atorerons and geve a different energy range avalidule to be measured sor each type of particle. These corrections were aplied to the energy distributions of particles from the thich target.

The ratio of the number of protong to tre number of deuterons in these two intervals is the correction that was applied to the experimental ratio. The ratis of ceuterons to protons fron a thin sulfur target when irradiated by of Mc bremsitrahlung is $0.15 \pm 0.04$.

\subsection{X-Ray Induced Radjoactivities (D. Jo Zafianano)}

The study of the decay soheme of $\mathrm{Te}^{129}$ (70 minutes half-life) has been completed. The decay consists of a simple beta-gamma cascade of eriergies 1900 and $440 \mathrm{kev}$, respectively, to the ground state of I129. The decay of 36129 is also being studied with colncidence scintillation spectrometers. There are apparently flve beta groups, with energies 1700, 1560, 1395, 1170, and 920 kev. Gamma-rays of energies $780,530,310$ and $160 \mathrm{kev}$ from the levels after the beta transitions are fitted into a consistent decay scheme. 
2. Solid State Studies

2.1 Thermal Conductivity (K) of Uranium (G. C. Danielson)

The thermal conductivity of uranium has been measured in the temperature range $100^{\circ} \mathrm{C}$ to $600^{\circ} \mathrm{C}$ by means of a static method which compares the unknown thermal conductivity to the thermal conductivity of Armeo iron. The data have been found to fit the equation

$$
K=0.348-1.83\left(10^{-4}\right) \mathrm{T}+2.95\left(10^{-10}\right) \mathrm{T}^{3}
$$

where $K$ is the thermal conductivity of uranium in watts/(cm)(degree $K$ ) and $T$ is the temperature in degrees Kelvin. Over the temperature range $400^{\circ} \mathrm{K}<\mathrm{T}<900^{\circ} \mathrm{K}$ the root-mean-square deviation is 0.011 . This error represents only the statistical error, however, and the total error in the thermal conductivity may be approximately $6 \%$. This error will be reduced by means of the matched thermocouples now installed in the sample and guard tube.

\subsection{Semiconducting Metallic Compounds (G. C. Danielson)}

Cu2se samples have been prepared with room temperature resistivities as high as $0.04 \mathrm{ohm}-\mathrm{cm}$. Resistivity as a function of temperature has been measured for one sample, but the data need verification. In the region $160^{\circ} \mathrm{K}-240^{\circ} \mathrm{K}$, the resistivity decreased as the temperature increased. The sharpest decrease occurred in the range $220^{\circ} \mathrm{K}-225^{\circ} \mathrm{K}$, in which range the resistivity varied as

$$
\rho=A e^{B / k T}
$$

where $B=2.5$ electron volts and $A=10^{-52} \mathrm{ohm}-\mathrm{cm}$. This curious result raises doubt about the validity of the data. Cu2se has been observed to exhibit a photo-voltaic effect when in contact with phosphor bronze.

\subsection{Measurement of Magnetic Field Gradients by the Hall Effect (G.C.Danielson)}

The Hall effect magnetic field gradient meter has been modified to measure relative gradients $(\mathrm{dH} / \mathrm{dx}) / \mathrm{H}$ as well as gradients $(\mathrm{dH} / \mathrm{dx})$. The device responded well to relative gradients in the range $0.02 \mathrm{~cm}^{-1}$ to $0.20 \mathrm{~cm}^{-1}$. Measurements of gradients have been made at magnetic fields as high as 10 kllogauss.

Excessive dependence of Hall coefficient upon field strength seems to limit the usefulness of this gradient meter.

\subsection{Electrical Properties of Thin Metallic Films (G. C. Danielson)}

Three runs to determine the conductivity of sodium films have been made with the present apparatus. In alI cases the resistivities of the sodium films have been extremely high (about one ohm-cm). Examination under a microscope revealed an extremely aggregated structure. 


\subsection{Heat of Sublimation of Dysprosium (D. E. Hudson and F.H. Spedding)}

New vacuum-cast samples of high-purity dysprosium have been studied by our mass-spectrometric technique. Seven new runs have been made on this metal, in additicn to two runs previously reported. The average heat of sublimation for all nine runs is $69.4 \pm 0.7 \mathrm{kcal} / \mathrm{mole}$ at a midrange temperature near $1230^{\circ} \mathrm{K}$. The best corrected average value for many runs on less pure cast material was $67.1 \pm 0.7 \mathrm{kcal} / \mathrm{mole}$. It appears that the improvement in purity gives rise to a significant $2.3 \mathrm{kcal} / \mathrm{mole}$ increase in the measured value of the heat cf sublimation. 
APPENDIX: LIST OF REPORTS FROM THE AMES LABORATORY

1. Reports for Cooperating Laboratories

ISC-437 (rev) G. H. Beyer, D.R. Spink, J. B. West and H. A. Wilhelm. Caustic Treatment of Zircon Sand.

ISC-443 Philip Phipps and D. J. Zaffarano. The Half-Lives of Some Short-Lived Low Z Nuclei Formed by Photonuclear Reactions.

ISC-468 A. L. Loeffler, Jr. and B. J. Ruth. Mechanism of Hindered Settling and Fluidization.

ISC-474 G. H. Murphy, D. F. Young, and R. J. Burian。 Progress Report on Friction Loss of Slurries in Straight Tubes.

ISC-482 M. E. Dooley and D.F.Atkins. A New Electronic Vacuum Dilatometer.

ISC-487 Ames Laboratory Staff。Physics. Quarterly Summary Research Report. January, February, March, 1954。

ISC-488 D。R。Wilder and E。S。Fitzsimmons。 Further Study of Sintering Phenomena.

ISC-490 A。I.Bureau, H。A.Austrheim, and D.J.Zaffarano. An Electron Injector for a $70 \mathrm{Mev}$ Synchrotron.

ISC-491 J。T。Williams。The Vanadium-Zireonium Alloy System。

ISC-492 K。 W。 Olson and $G$ 。 C Danlelson. Variations of Electrophotoluminescence Phenomena with Frequency of Applied Field.

ISC-494 M。R。Nadler and E。S。Fitzsimmons。 Preparation and Properties of Calcium Zirconate.

ISC-500 B。A。Rogers and D.F。Atkins。The Zirconium-Columbium Diagram.

ISC-501 M。 Margoshes and V。A.Fassel。 Infrared Functional Group Analysis of Aryl Silanes.

ISC-502 M。 Margoshes and V。A。Fassel。 The Infrared Spectra of Aromatic Compounds. Io The Out-of-Plane $\mathrm{C}-\mathrm{H}$ Bending Vibrations in the Region $625-900 \mathrm{Cm}^{-1}$ 。

ISC-508 Ames Laboratory Staff。Physics。 Quarterly Summary Research Report. April. May, June, 1954。

ISC-514 D。R。Wilder and E。S。Fitzsimmons, Improved Calcium Fluoride Shapes.

ISC-516 V。A。Fassel, B. Quinney, I。 C.Krotz and C。F。Lentz。 Quantitative Spectrographic Analysis of the Rare Earth Elements。

$$
\text { r., n } 18
$$


2. Papers Published in Sclentific Journals

Altshuler, S. and J. F. Carlson

ISC-47 Time Dependent Variational Principle. Phys. Rev. 95, 546-548 (1954).

Chiotti, P. Adaptation of a Geiger-Counter X-Ray Diffractometer for ISC-412 683-688 (1954).

Dickinson, J. M., O. N. Carlson and H. A. Wilhelm The Niobium-Vanadium Alloy system. J. of Metals $\underline{6}$, AECD-3544 915-918 (1954). $|s c-39|$

Duke, F. R. Qualitative Theory of Electron-Transfer Mechanism. Record of Chem. Prog。15, 55-59 (1954).

Duke, F. R. and V. C. Bulgrin

$$
\begin{aligned}
& \text { TEt-4.41 Give Kinetics of the Periodate Oxidation of Ethylene } \\
& \text { J. Am. Chem. Soc. } 76,3803-3806 \text { (1954). }
\end{aligned}
$$

Duke, F. R. and R. Laity Transport Numbers in Pure Fused Salts。 J.Am. Chem. Soc. $756-796 \quad \underline{76}, 4046-7(1954)$.

Duke, F. R. and P.R。 Quinney IS - 4.8\% The Kinetics of the Reduction of Perchlorate Ion by Ti(III) in Dilute Solution. J. Am. Chem.Soc。 76 , 3800-3803 (1954).

Fassel, V. A. and R. H. Heidel Isc-313 Fluorescence Spectrometric Determination of Terbium. Anal. Chem。26, 1134-1137 (1954).

Fritz, J.S. and M. O.Fulda TSC Titrimetric Determination of Zirconium. Anal. Chem. FSC-382 26, 1206-1208 (1954)。

Herwig, L. O. and G. H. Miller Relative Ionization Yields for Fission Fragments in IsC-498 Various Gases. Phys. Rev。 95, 413-417 (1954)。

Horrocks, D. L. and A. F。 Voigt ISC-479 Half-Life of Thallium204. Phys: Rev. 95, 1205 (1954). 